\title{
A REFLECTION ON DEVELOPMENT OF INDIGENOUS LANGUAGES FOR KNOWLEDGE CREATION AND SHARING IN A GLOBALISING WORLD: A CASE OF ESAN LANGUAGE, NIGERIA
}

\author{
Obinyan, Gabriel Aine \\ Department of Library and Information Science \\ Ambrose Alli University, Ekpoma \\ Email: obinyantoyin@gmail.com or ainetoy@yahoo.ca \\ \& \\ Aziegbe, Mabel Ejoghoye \\ Department of Modern Languages \\ Ambrose Alli University, Ekpoma \\ Email: ejoghoyefame@gmail.com or mabaziegbe@ yahoo.com
}

\begin{abstract}
Humanity, culture, societal development and language issues are mutually reinforcing much as they are intricately interwoven in a non-ceasing dynamic interrelationships within the matrix defined by language standardization or development, acquisition and use that mostly take up central place as unifying and propelling forces in language discourse. Within the confines of globalization which is neither homogenization nor convergence; but the beginning of drawing on the strength of indigenous capabilities to create knowledge ecology that would enliven socio-economic and scientific development of the world in far reaching interconnectivities and relationships across every clime, issues pertaining to language development, acquisition and use become imperative. It is against this background that this paper examines the development/standardization, acquisition and use of Esan language as one of several Nigerian indigenous languages to promote scientific and technological development through knowledge creation, preservation and dissemination. The obsession of using western model and epistemological outlook to achieve appropriate scientific and technological development to the utter neglect of home grown and culturally distilled efforts were also examined. In the light of the dare consequences and the harsh conditions globalization imposes on developing nations, this paper highlights standardization and use of indigenous languages in chatting appropriate trajectory for effectual developmental efforts in fast shrinking contemporary world.
\end{abstract}

Keywords: Humanity, culture, development and language, Globalization, Indigenous capabilities, Knowledge creation and Technological development

\section{Introduction}

In Nigeria, the politicization of issues concerning language development, acquisition and use is worrisome to the extent that no government since independence in 1960 has shown appreciable level of conviction and readiness to commit funds, material and human resources to the development and creative use of any of her existing indigenous languages besides some sketchy policies formulated to underpin some official interest in Hausa, Ibo and Yoruba being the three major indigenous languages. As far as language issues are concern, irrespective of the resources encapsulated, nobody pays attention that is anywhere close to the attention paid 
to the development and creative use of English language and of late French. This is not encouraging enough for a country in dire need of development and favourable socio-cultural, economic and technological visibility in a globalizing world. Our history, our culture, our languages and literatures; our philosophy, the totality of our artistic creativity - all these define and to some extent delimit our humanity (Dada, 2007) which our forbearers strove to communicate, besides the spoken words used daily for communication with others, through information encoded in drawings/paintings on walls of caves, in carvings, sculptures, etc. Within this all embracing mix and contemplation, Osundare (2015) talked about the possibility of contemplating and analysing the formal properties of a work of art (framed in the language of choice of the author) without doing violence to the content; in which case, we can, for instance admire the intricate strokes of painting, the luminescence of its colours, even the shape of its canvass, before going on to its content, its subject-matter, and from there to its meaning and import.

Humanity started with being human on the basis of language development, acquisition and use, and not on the springboard of science and technology that has inexorably become a dominant index in measuring societal development, advancement and wellbeing. The seemingly over weighted importance assigned to the use of technology in the determination of societal wellbeing could be supported by the views of Acemoglu and Robinson (2013) that technological change is only one of the engines of prosperity, but it is perhaps the most critical one. Using science and technology as a dominant index of measurement of societal development and wellbeing is an aberration, an inverted and west-ward skewed model that in most cases do not accommodate the consideration of other aspects of culture that are integral to the totality of man. Through creative thinking involving the use words and more words extracted from human language, intricate but beneficial worldviews that could improve human existence through "observation, memory and imagination" were birthed for technology also birthed through the same process of critical thinking to work on to produce products like cars, rockets, ships, computers, etc. Humanity where language belongs predates technology hence the assertion that technology in human history has always been made to solve the problems human beings want it to solve at any given point in time such that determined and informed minds can respond appropriately to changing socio-economic and political conditions of their time.

The move to balance the prevailing practice of using the inverted and west-ward skewed epistemic model alone as a means of measuring and projecting our worldview as a developing nation without recourse to using humanistic values, is to herald a new and 
ineffectual mechanistic societal order devoid of human touch or feelings from several indigenous cultures in a globalizing world. In order words, balancing the interrelationships between humanity and science/technology using the instrumentality of indigenous languages, their development, acquisition and creative use in introspection, communications, publishing and dissemination of knowledge for development is to give added form and hues of a much more beneficial nature to the interdependency among nations of the world. The intention in this paper is to instigate and open up the massive value adding systems and the unique worldviews our indigenous people can offer to set new standards for human and cultural development in our collective march towards higher order global civilization.

We believe this is practicable and the practicality as it relates to the development and creative use of indigenous languages is hinged on the fact that through the instrumentality of indigenous languages hitherto relegated, majority of the developing nations of the world like Nigeria will be well positioned to be able to contribute unique social and moral values, knowledge and efficacious herbs use, peculiar scientific and technological worldviews into the growing current of globalization for a roundly beneficial world of tomorrow. The thrust of globalization as a concept and a process, encapsulates the growth of connectivity among people and nations on a planetary or global scale. Unfortunately as the situation is at the moment, globalization does not operate on the basis of equity or respect for fair play in the creation and distribution of global wealth. Globalization involves the reduction or elimination of barriers to trans-world contacts (Scholte, 2005) along supposed lines of socio-economic, cultural, scientific and technological mutual aids.

The ability to generate and effectively use knowledge according to Tagoe (2016), contributes greatly to the creation of wealth for nations. Arguing further, Tagoe (2016) posits that African countries have serious challenges in generating, accessing and disseminating knowledge as well as a near absence of effective innovation systems. When as a nation you map and appraise the functionality of your socio-economic, cultural and political structures using purely borrowed lenses against the backdrop of equally borrowed epistemic model without adaptation, you certainly will fall short of expectations if not totally stagnated. As a people, we have operated over the years with a language that has disenfranchised majority of our indigenous people from actively contributing their quota to national development. The predominant use of second languages like English and French in our polity as a nation is destructive to our teaming indigenous languages and the uncommon worldviews which their use alone can offer humanity. In this same rib of thought, Acemoglu and Robinson (2013) observe that the profitability of European colonial empires was often built on the destruction 
of independent polities and indigenous economies around the world... According to them, it happens in the Caribbean Islands, where, following the almost total collapse of the native populations, Europeans imported African slaves and set up plantation systems. In what could be adjudged lamentation over the experiences of the Caribbean Islands in Europeans' hands, Acemoglu and Robinson (2013) made the following submission that-

We will never know what the trajectories of independent city states such as those in the Banda islands, in Aceh, or in Barma (Myanmar) would have been without the European intervention. They may have had their own indigenous Glorious Revolution or slowly moved toward more inclusive political and economic institutions based on growing trade in spices and other valuable commodities. But this possibility was removed by the expansion of the Dutch East India Company. The company stamped out any hope of indigenous development in the Banda Islands by carrying out it genocide $271 \& 272$

The predominant use of foreign languages like English and of late French in Nigeria is genocidal to indigenous languages development; their creative use, the wisdom they encapsulate and the uncommon worldviews they can offered toward the development of humanity. English language is rated across the world as the foremost language of science. Though politically satisfying to those that lay claim to the ownership of the language, it is a destructive retardant to the existing indigenous languages in the community or country where English is adopted as official language. It is, however, primitive to luxuriate in a situation where the adoption and use of one major language of the world would slow down the development, and on the extreme completely stamp out any hope of developing indigenous languages like those in the Banda Islands. If some living things could be protected because they are part of an ecosystem despite their harmful nature, indigenous languages with all their potentials should be much more protected from extinction.

Progress in general terms is difficult for Nigeria like many other developing nations to attain because of utter neglect of adapting western worldviews with indigenous capabilities. Regrettably till date, technological ideas imposed by the advance countries on the developing world in place of internally generated ones through culturally mediated critical thinking, inventions and/or adaptations has yielded little or nothing. The perpetuity of this approach, that is, the imposition of ideas from without for acceptance/adaptation has aversely influenced and subjugates cultures that were ill prepared and unable to readily draw on their indigenous intellectual capabilities to filter and cultivate for effective implementation the processes underlying the imposed know-how. Situations like this have been recurring for 
nations lacking in the proficient use of adopted or acquired second languages to access and create new knowledge and information for appreciable development; bearing in mind that language is a conduit for transmission of people's culture, norms, ideas and belief systems (Emeka-Nwobia, 2015). A lost language is a monumental loss in terms of unique worldviews, resources and cultural capabilities no other cultural space or location can replicate. Lack of serviceable indigenous language is making it difficult for Nigeria and other developing nations to get to a point where discovery and sustainability of suitable threshold for technological takeoff to be guaranteed. In this circumstance, to find expression for our value adding capabilities that will meaningfully enriched ongoing globalization process will remain impracticable for scores of decades to come.

Creative use of the language our forbearers bequeathed to us as a supreme tool of communication' (Osundare, 2015), will very well assist national definition and redefinition of our value systems that will effectively direct and drive our knowledge creation assistive thought pattern and language use. To this end, culturally relevant information and knowledge could be generated and communicated through functional language use in order to develop means of sustaining flexible technological applications to solve societal problems. It is within the confines of this nature that mother tongue and scientific/technological issues interact hence Egboghare (2011) quoting Prah (1995) observed that scientific practice is a mode of intervention. Demonstrating the value of mother tongue in science, Prah (1995) had averred that concepts, abstract notions and scientific linguistics tools are most accessible and provide greater facility for effective usage if the concepts, abstract notions and scientific linguistics tools are grounded in the language which provides and will continue to provide systematic grid for interpreting and intervening in reality.

\section{Globalization, Indigenous Language Capability and Knowledge Generation and}

\section{Knowledge Sharing}

Globalization is associated with some forces capable of either catalysing socioeconomic growth and development or suppressing the true essence of a nation depending on the side of developmental divide the nation finds itself or depending on the preparedness of the nation to adapt and carve out a capability niche for itself among the comity of nations. India for instance is noted for software development, Japan notable for ship building amongst other capabilities, Chinese for acupuncture, USA known to be first in so many things and in so many areas to mention just a few nations. In the early 1990s globalization was launched as a new epoch in world history embodied in the international system that replaced the Cold War system after the fall of the Berlin Wall. To empower indigenous language across the 
globe for higher order and scientific discourse within the limit of globalizing tendencies is to break the barriers of limitations imposed by long time adaptation and use of domineering foreign languages. Operating from the platform of strength as provided by the use of well developed indigenous language creatively for academic discourse, the communities of people that own the language would have been sufficiently empowered to be able to transact cultural goods, knowledge and services as well as negotiate cultural space and experience (Egbokhare, 2011). No language is an island onto itself hence its predisposition to borrowing of terms from other languages for standardization as well as to effectuates a more beneficial use. According to Osundare (2015), every language has within its system a loophole, an elastic edge for adventurous user to widen and stretch. Looking at the polysemic propensity of language within the confines of field-oriented activities, Osundare (2015) further observed that a new addition to existing human activities always has repercussions for language and style. Language in turn reacts either by accommodating new lexical entries or extending the referential umbrella of existing ones (or both).

In the evolution of language development and democratization through writing, Greeks as averred by Egede (2017) played remarkable roles. Arguing further Egede (2017) noted that however profound and phenomenal Greek civilization might have been, it did not flourish in isolation because Greeks were skilled imitators; and they improved on what they borrowed from elsewhere. In such a circumstance as this, any indigenous language like Esan can enrich its register by borrowing terms and concepts from science and technology, from already established languages such as English and French and even Greek provided such borrowing is properly coordinated to cater and account for all fields of academics and discourse.

\section{Status of Indigenous Languages in Nigeria}

With language, appropriate knowledge conversion process that can lead to development of healthy and sustainable synergy between science and the humanities that could broaden the horizon of research for national development could be guaranteed for an enrich global village on an unimaginable scale. Language generally is a system of symbols that can be strung in an infinite number of ways for the purpose of communication of abstract thoughts (Henslin, 2003). The dignified position assigned to English in the development of Nigeria has in turn downgraded the indigenous languages to the background and as well made less significance in the scheme of things in the country (Emeka-Nwobia, 2015). As Obinyan (2010) had argued, the question of developing indigenous Nigerian languages for teaching and scientific communication has been a daunting and protracted one. To some 
Nigerians, it is a futile initiative and a misplacement of priority at best to think of committing hard earned resources to the course of developing indigenous Nigerian languages each for effective communication and professional use since there are well over 250 of them.

Indigenous languages can be made adequate for effective discourse in everyday interactions in socio-economic and scientific spheres through borrowing /or adaptation of terms. In Esan language for instance gbi eva yi eva or better still gb'eva y'eva is $2 \mathrm{x} 2$ (that is, two times two), gbi enęn yi enęn or gbe'nęn yi enęn is 4 x 4 (four times four), etc. Higher order multiplication such as 4 ! - four factorial has no existing term in Esan language. The term being suggested for factorial in this paper is ifatoria. In the case of 4 ! the Esan language equivalent will be bhi ękęle ifatoria, gbe'nęn yi enęn (that is, inside factorial multiply four by four) in the order of $1 \times 2 \times 3 \times 4=24$. Irrespective of the unhealthy politics being played in Nigeria and elsewhere regarding indigenous language development and use as a national language, the owners and speakers of indigenous languages must make spirited efforts to prevent such languages from attrition and in the process enabled the human communities to contribute their value adding language enabled/related resources to ensure a much profitable interdependency and interconnectedness in ICT mediated shrinking world or global village.

According to the New Encyclopaedia Britannica (1998), language is the expression of ideas by means of speech sounds combined into words which are combined into sentences. As far back as 1963, Sapir defined language as a purely human and non-instinctive method of communicating ideas, emotions and desires by means of voluntarily produced symbols. Every physiologically and mentally normal person acquires in childhood the ability to make use, as both speaker and hearer, of a system of vocal communication that comprises a circumscribed set of noises ... by means of which he is able to impact information, to express feelings and emotions, to influence the activities of others, and to comfort himself with varying degree of friendliness or hostility toward persons who make use of substantially the same set of noises (The New Encyclopaedia Britannica, 1998). Language being the system of conventional sounds and symbols developed over time by a specific human population or grouping is a means of expressing and exchanging thoughts, feelings, information and knowledge, consists of vocabularies and rules of grammar, syntax, and orthography (Reitz, 2004); orthography being officially approved system of spellings in a given language. It is incontrovertible, therefore, that any indigenous language backed by orthography is straining towards some forms of standardization in readiness for widespread adaptation and use in formal and informal circles provided it is not lacking in vocabularies. 
At some point in time, all human languages for that matter had native speakers to who such languages are indigenous/mother tongue or first language. Expectedly, the mastery of mother tongue by any group of persons will prime such persons in readiness for easy acquisition of a second language (to be bilinguals) and a third or more to be polyglots. This is one of the aspects that portray the utilitarian value of Indigenous language, being a language some culturally bounded people use to communicate and share commonly understood codes and symbols to better their lots. With minimal efforts, owners of any indigenous language as English is to the Britons are expected to be able to understand the dynamics of their immediate environment, and explore available resources from the platform that is culturally strengthened amidst mental capabilities provided by the indigenous language. Teach the children using mother tongue was the recommendation of Ife project of many years gone by because children learn better that way.

Regrettably, successive government in Nigeria has consistently demonstrated lack of will power and commitment to drive effective implementation of the cardinal recommendations of Ife project to a logical conclusion. Government made some feeble efforts to implement the recommendations of the Ile-Ife project or experiment of teaching children in their formative years in their mother tongue. In spite of the higher order effectiveness and functionality inexorably ascribed to teaching and learning using indigenous language in Nigeria, many years on, the implementation of the Ife project recommendation is stalled for lack of sustained financial and political commitment. That majority of Nigerians are not proficient beyond speaking any of the existing indigenous languages is an attestation to the failed project.

An earlier study conducted on the development of Esan language for effective communication and professional use by Obinyan (2010) reports the lamentation of the entire 1500 respondents that participated in the study regarding the existence of a very high percentage of Esan people that were not literate - profoundly or partially - in reading and writing scripts in Esan language. Although the respondents were unanimous in their submission that the problem was attitudinal, part of the findings of the study remain that the people of Esan still found it more prestigious to speak and study English language - the language they claimed is the language of the elites. The question now is - to what extent has the depressing situation changed for the better? Which direction is the language tending in terms of development and proficient use? What is the relevance of developing Esan language in a globalizing world? Responding to these questions, the paper attempts to provide a framework for critical reflection on the need for the development and standardization of 
indigenous languages in Nigeria in order to secure widespread usability for development in the face of rapidly evolving globalization experience.

\section{Issues of Language and Humanity}

As long as people have wondered about the world, they have been intrigued by the mysteries of human nature. The most commonplace activities of our lives - the things we take for granted - can be quite puzzling when we try to understand them systematically. At the centre of humanity is language and the making of a serviceable language is humanity. The connecting strand between humanity and language is communication which according to Littlejohn and Foss (2008) is one of those everyday activities intertwined with all of human life so completely that we sometimes overlook its pervasiveness, importance, and complexity. Human language and communication and the dynamic complex created as a consequence of the dependency and the mutually reinforcing interrelationship thereof are central to human life insofar as every aspects of human daily lives is affected by our communication with others, as well as by messages from people we do not even know - people near and far, living and dead. The development of shared codes of our indigenous languages should be taken seriously as the effectiveness/success or otherwise of human efforts in knowledge discovery and transfer depend on communication as a primary and constitutive social process. According to Craig (1999), communication is the primary process by which human life is experienced; communication constitutes reality.

\section{Globalization and Imperativeness for Standardizing Esan Language}

For a society like Nigeria to have her impact felt in a world that is fast turning into a global village, efforts must be made to weaken the perceived cultural imperialism through proactive publishing that could strengthen indigenous value systems and ideologies with inherent potentials to positively affect lives and contribute to the development of mankind (Obinyan, 2011). The seriousness of standardizing Esan language and the rest indigenous languages in Nigeria under the influence of a globalizing economy can be appraised against the submission of Sutz (2002). According to him, globalization is not homogenization, it is not convergence, nor is it the end of history, if by that we mean some sort of final uniformity. As Sutz (2002) further argued, globalization imposes harsh conditions which are hardly ever discussed: one of these is the obligations to maintain an active and changing relationship with knowledge so as to hold open the possibility of escaping at least partially, from a situation of almost total subordination. To this end we would like to submit that globalisation being not the end of history, it could be the beginning of drawing on the strength of indigenous 
capabilities and knowledge creation to enliven socio-economic and scientific development in far reaching interconnectivities and relationships across the globe. Reflecting on the issue of the dismal performance of Nigeria so far to warrant a paradigm shift from what is not working and obsolete to what will work; Egbokhare (2004) has avers that:

Nigeria is like a rotten boat. For forty years after independence, with three or four development plans in the bin, we are still confronted with mundane issues of survival. We may speak of our problem euphemistically as that of underdevelopment. Our reality is that we are confronted with the problem of the provision of basic infrastructure, the problem of absolute poverty, corruption, poor leadership, ethnic and religious conflicts, illiteracy and illliteracy. We continue to insist on paradigms that have run their courses. We maintain a consciousness best confined to the covens of ignorance. ${ }^{\mathrm{P} 1}$

The need to turn to the use of indigenous languages to release the knowledge and intellectual capital locked up in them to assist a more acceptable pace of development in the face of the harsh conditions (such as marginalization, and domination, and isolation or segregation) globalization has imposed on developing nations including Nigeria become imperative. Language is not only very essential in research, communication and in business; it is also a resource which can be deployed to improve humankind. In this regard, the nature of the indigenous language understood by man with special reference to the degree of its development in terms of the meaning it can convey vis-à-vis the mental images it creates in human will determine the reach and limit of Nigeria influence in international arena in a shrinking world of contemporary times.

\section{Use of Foreign vis-à-vis Indigenous Models}

Construction of models using indigenous language and value system to drive our worldview and development could be term in broad sense as composite products of creative collaboration between native epistemic efforts and science; to borrow a rib of thought from Umukoro (2001). Nigeria's development problems indeed Africa's, are not due to the dearth of human and material resources, but they are the result of a failure of will, a poverty of responsibility and a pristine taste for material acquisition (Egbokhare, 2004). Writing in the 1980s Opki (1982) as reported by Nwaozuzu (2007) asserted with an air of finality, that standard Igbo poses a language problem for actors on stage. The views express by Okpi have continued to be parroted by successive commentators on Igbo literary drama without subjecting them to the demands of research and objectivity (Nwaozuzu, 2007). Attitude such as this is heinous and inimical to research and use of indigenous languages to liberate the sensibility of our society to chart a new course to greatness. 
To this end we reiterate Obinyan's (2014) developmental trajectory model depicted in Figure 1 as viable path that could assist Nigeria as well as other African nations using their indigenous-value-enriched-intellectual-capital to add significant worth to humanity in a globalizing world. In the model, two trajectories could clearly bring about human and societal development at differing rates was depicted. Starting from the assumed origin of human developmental efforts as marked by the letter $X$ at the centre of the model, began the outward spiralling trajectory of human efforts at development. Advancement along the spiral trajectory has gone so far for the whites with their own model and epistemic worldviews that they have developed to advanced from point $X$ to $Y$. With the claims to the slowing mistreatment received from the west coupled with internal problems of low self esteem, corruption, poor educational systems, bad governance, misplacement of priorities and wasteful spending by Nigerian and African leaders, African nations that adopted the use of western model and epistemic worldviews without adaptation had advanced quite swiftly (?) from the starting point $X$ to $X^{1}$ where the Nigeria nation is presently with the assurance of becoming one of the twenty most developed nations in the world by the year 2020 - as encapsulated in the nation's popular vision 202020.

If it took Africans inclusive of Nigerians moving at already established and known developmental pace, many years to achieve the feat of moving from point $X$ (the assumed origin) to point $X^{1}$, no one can accurately predict how long it would take Nigeria to advance or progress from point $X^{1}$ to the probing and non-static point $Y$ if the choice of our developmental trajectory and epistemic worldviews are maintained within the western formulated paradigm. Even if $Y$ is static, how long still will the journey take a nation with unhelpful thoughts, foggy - governance, research and developmental efforts to reach destination $Y$ ? US is already championing the course of building smart cities where means of transportation will be driverless cars. Drone technology is already available to them; the mobilization of Silicon Valley to join the process is as good as the project being accomplished. Of what use is smart city or self-driving cars to the nation Nigeria when achievement of self sufficiency in food supply is still a mirage? Following trajectory $X^{l} Y^{l}$, the recommended path paved with unyielding developmental resolve for/by the black race, the world would have been jolted to expect appreciable worldviews and unique discoveries that will without doubt add values to humanity and the corresponding civilizing hues and predispositions. In this position, we would have cultural goods, knowledge and services to transact from the position of strength of our established cultural space and experience that will hold their relevance in any smart city. 


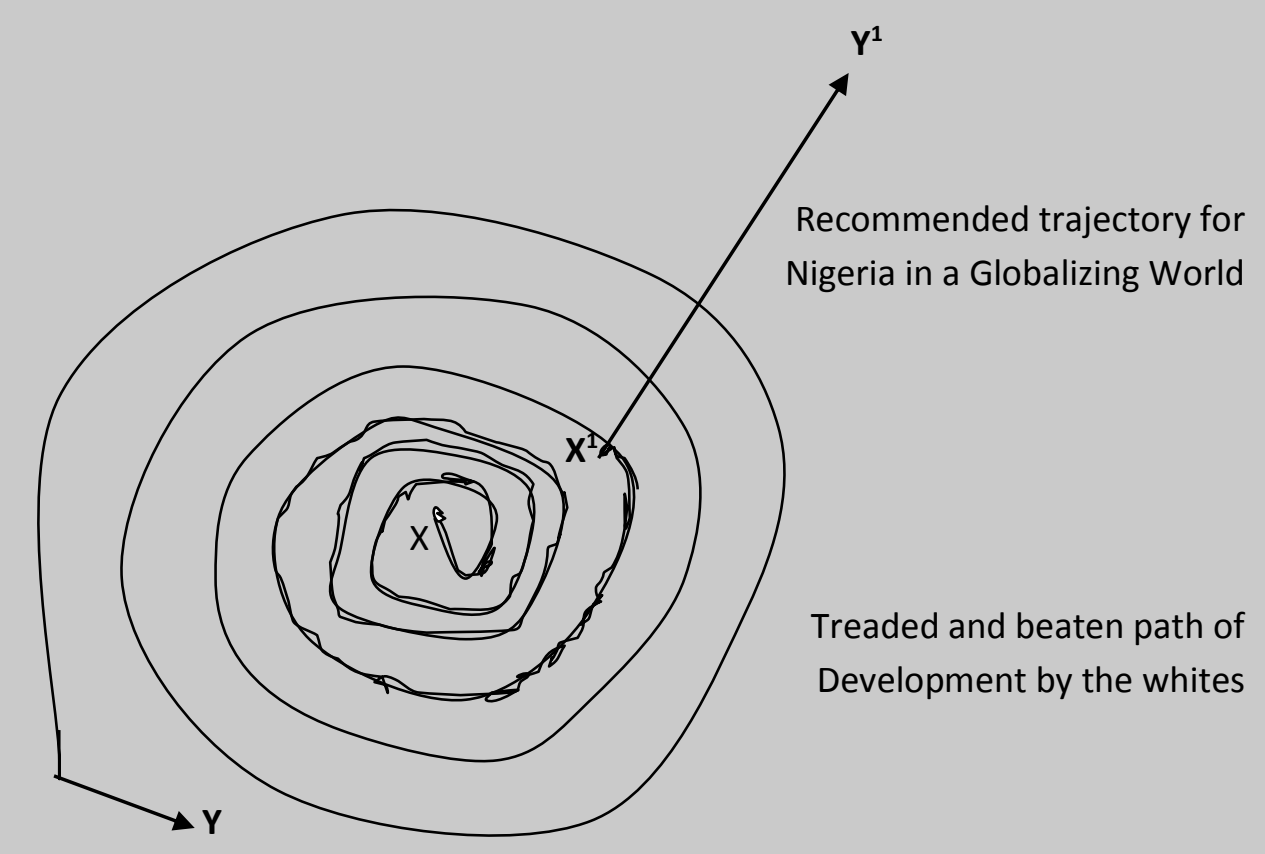

Figure 1: Developmental Trajectories

(Adopted from Obinyan's 2014 model)

The thinking is that when trajectory $X^{l} Y^{1}$ is followed with determination, the new direction will provide a lasting avenue for the Blacks to lucidly express and communicate their consciousness and worldviews creatively to mediate a beneficial in a shrinking world - an 
evolving global village - provided bad governance, tribalism, and xenophobia, fantastic corruption among other low order and demeaning ways of life are done away with. In a nondeterminate effort made by Nigeria along the recommended development trajectory for Africans at the wake of Ebola outbreak, the result achieved was quick and astounding. That the western model could not appreciate the magical antidote that ended the siege of Ebola in Nigeria should not be regretted. Similar feats in other spheres in quick succession will enthrone the desired recognition.

\section{Conclusion}

It is obvious we are at an embryonic stage of trying to look to at world through our cultural consciousness to secure an availing developmental drive for our society. Using indigenous knowledge system, we can easily give worldview physical and implementable expressions; a situation that defied many years of countless efforts made under western epistemic efforts and models. Empowering our languages for far reaching discussions and knowledge discovery, we must discountenance the discouraging comments that must come from cynics in the interest of status quo remaining when issues of language policy is concerned in Nigeria. Our training in creativity both in thoughts and in actions should be deployed to drive our resolve to achieve professorial marks in every facet of our socio-cultural, economic and political lives. Nigeria indeed Africa can only be better. Let English remain on the landscape of consideration for now we develop alternatives. 


\section{References}

Acemoglu, D. and Robinson, J.A. (2013). Why nations fail: the origins of power, prosperity, and poverty. London: Profile Books Ltd.

Craig, R. T. (1999). Communication theory as a field. Communication Theory 9: 119-61. Davenport, T.H. and Prusak, L. (2000). Working Knowledge: How Organizations Manage What They Know, Harvard Business School Press, Boston, MA.

Dada, P. O. (2007): Metamimesis and metatextuality: the raft and another raft. Language and Literature in A Developing Country. Essays in Honour of Professor Benson O. A. Oluikpe, B. N. Anasiudu, G. I. Nwaozuzu and C. N. Okebalama Eds. Onitsha: Africana-First Publishers Ltd. Pp. 154-164.

Egbokhare, F.O. (2004). Breaking barriers: ICT, language policy and development. Ibadan: Postgraduate School, University of Ibadan.

Egede, B. N. (2017). Modern African poetry: between the creative imagination and the critical impulse. An Inaugural Lecture delivered at Ambrose Alli University Ekpoma. Ekpoma: Inno Printing Press.

Emeka-Nwobia, N. U. (2015). The Place of indigenous Nigerian languages in national development. Research on Humanities and Social Sciences, 5(12): 112-116.

Egbokhare, F. O. (2011). The Sound of meaning. An Inaugural Lecture delivered at the University of Ibadan. Ibadan: University of Ibadan Press.

Ezeude, J. I. (2007). Innovational approaches and methods in language teaching: is Nigeria of the times? In Language and Literature in a Developing Country: Essays in Honour of Professor B.O.A. Oluikpe. Edited by B. N. Anasiudu, G.I. Nwaozuzu and C. N. Okebalama. Onitsha: Africana-First Publishers, 202-213.

Ezikeojiaku, P. A. (2007). Indigenous languages for science and technology. In Language and Literature in a Developing Country: Essays in Honour of Professor B.O.A. Oluikpe. Edited by B. N. Anasiudu, G.I. Nwaozuzu and C. N. Okebalama. Onitsha: Africana-First Publishers, 114-123.

Henslin, J. M. (2003). Sociology: A down-to-earth approach, $6^{\text {th }}$ ed. Boston, Massachusetts: Allyn \& Bacon

Littlejohn, S. W. and Foss, K. A. (2008). Theories of human communications, Ninth Edition, Belmont, CA: Thomson Wadsworth.

Nwaozuzu, U. C. (2007). Text, performance and theatricality: a stage director's evaluation of contemporary Igbo literary drama. In Language and Literature in a Developing Country: Essays in Honour of Professor B.O.A. Oluikpe. Edited by B. N. Anasiudu, G.I. Nwaozuzu and C. N. Okebalama. Onitsha: Africana-First Publishers, 73-77.

Obinyan, G. A. (2011). Acquisition and Application of Information and Communications Technology and Staff Training as Factors Affecting Sustainable Development of Book Publishing in Nigeria. Unpublished PhD thesis submitted to Library, Archival and Information Studies, University of Ibadan. Ibadan. 
Osundare, N. (2015). Cautious paths through the bramble: a critical classification of style theories and concepts. Ibadan: Hope Publications

Prah, K. K. (1991). Culture, gender, science and technology in Africa. Windhoek: Harper Publications.

Reitz, J. M. (2005). Dictionary for Library and Information Science. London: Libraries Unlimited.

Scholte, J. A. (2005). Globalization. Microsoft Encarta Encyclopedia.USA: Microsoft Corporation, 1-6.

Sutz, J. 2002. Globalization: some reflections from Latin America. Media Culture and Society. 24(5):613-619.

Umukoro, M. M. (2001).The Performing artist in academia. Being the 11th Faculty Lecture delivered in the Faculty of Art, University of Ibadan. Ibadan: Caltop Publications. 